Jürgen Essletzbichler, London

\title{
Generalized Darwinism, group selection and evolutionary economic geography
}

\begin{abstract}
The paper contributes to the development of evolutionary economic geography in the following ways. First, it summarizes the conceptual building blocks of Generalized Darwinism (GD) and argues that an evolutionary theory based on GD encompasses and complements those based on the principle of emergence and path-dependence. Second, the paper discusses the notion of group selection considered important for rejecting methodological reductionism and developing a multi-level evolutionary theory that opens new opportunities for the application of GD in economic geography. Third, the paper shows how the meta-theoretical framework can be used to organize existing work in evolutionary economic geography, identify conceptual and empirical blind spots in current research, but also contribute to theory formulation and bridge currently disconnected subfields in economic geography more generally.
\end{abstract}

Keywords: evolutionary economic geography; Generalized Darwinism; group selection; multilevel co-evolution.

\section{Introduction}

Economic geography is one of many disciplines importing evolutionary metaphors, ideas, concepts and principles that form the building blocks of a fledgling evolutionary economic geography (EEG). FRENKEN (2007), Boschma/MARTIN (2010) and special issues in the Journal of Economic Geography and Economic Geography offer good overviews of this work. This paper does not attempt to imitate those efforts and offer a complete account of all the work on EEG often loosely tied together by common metaphors rather than carefully derived arguments from broader evolutionary principles, but suggests to build EEG on and develop stronger conceptual links with Generalized Darwinism (GD) (ESSLETZBICHLER/RIGBY 2007; 2010; ESSLETZBICHLER 2012). "Darwinism is a general theoretical framework for understanding evolution in complex population systems, involving the inheritance of replicator instructions by individual units, a variation of replicators and interactors, and a process of selection of the interactors in the population" (HodGSON/KNUDSEN 2010, 65).
While the development of GD and its application to sociocultural evolution is very much contested and not without problems (VROMEN 2007; SCHUBERT 2012; BROWN 2012), it brings into focus the relationship between the three principles of variation, selection and retention absent from alternative starting points in EEG including complexity science (PLUMMER/ SHEPPARD 2006; MARTIN/SUNLEY 2007), the principle of emergence (MARTIN/SUNLEY 2011) or path-dependence and lock-in (GRABHER 1993; ARTHUR 1994; Martin/SunLey 2006; MARTIN 2010). Complexity theory and the principle of emergence focus on the creation of variety and endogenous transformation of entities but explain insufficiently how existing variants are maintained over time or why certain variants succeed or fail. Path-dependence stresses the retention of existing information and knowledge and the fact that certain outcomes are impossible if particular pathways have not been chosen in the past. And while the concept of path-dependence has been supplanted with processes of path creation (MARTIN 2010), it is still unclear why certain alternative paths are chosen while others disappear. 
GD, while situated at a high level of abstraction, examines how populations of heterogeneous entities evolve through interaction among themselves and with the environment that they help to shape. Variation is generated through endogenous transformation and emergence of new properties, through chance and deliberate search for improvement by intentional actors. Information about successful adaptations of phenotypes (interactors) is passed on over time by genotypes (replicators) that impede instantaneous adjustment to changes in the environment. It preserves variation necessary for selection to occur. Selection entails that those interactors with traits that fit the locally and historically specific environmental context better are characterized by higher survival rates and in turn, higher rates of replicative success. Darwinism offers an algorithmic logic predicated on a feedback loop between variety, inheritance and selection that can explain adaptive complexity. GD is not contradicting work on path-dependence or complexity science, but encompasses and complements it (KaUfMANN 1993; DENNETT 1995). Hence, GD is a broader framework that offers a way to organize existing work in EEG and contributes selection as complementary mechanism to the creation and retention of variety to close the explanatory loop for interpreting change in complex population systems.

Applying GD to economic geography then requires an understanding how the abstract principles of variation, selection and inheritance can be operationalized to explain the historically specific, inconstant, uneven and differentiated geography of capitalism. For this purpose, section 2 synthesizes and builds on HoDGSON/KNUDSEN (2010) who develop the abstract conceptual building blocks of Darwinism, explains why it may be preferable to complexity theory or path dependence as starting point for the development of EEG, dispels with a number of myths generally associated with Darwinism such as survival of the fittest, selection as optimization process, and genetic determinism, but also highlights the limits of those abstract principles to explain evolution in particular domains and raises a number of potential problems with a Darwinian evolutionary approach. Section 3 focuses on the importance of group selection for the development of an EEG and reiterates the need for ancillary hypotheses to bridge the abstract explanatory scheme of Darwinism with concrete problems encountered by economic geographers. Section 4 employs GD to organize existing work in EEG currently focusing on the creation and retention of technological, product and industrial variety but neglecting the role of selection to trim existing variants. A stronger conceptual link with evolutionary theory would help to clarify the theoretical and empirical contribution of an evolutionary interpretation to our understanding of processes shaping the inconstant geography of capitalism. Because economic geography tends to focus on entities above the firm (social relations, culture, aggregate regional change), the introduction of supra-firm entities exerting causal power on individuals and firms also entails an opportunity for economic geographers to contribute to theory development in evolutionary economics. In the end, the utility of an abstract theoretical framework will be judged by its ability to generate research hypotheses and insights in explaining actually observed empirical phenomena and not the elegance or logical closure of the theoretical edifice (VROMEN 2004). This paper proposes that GD may offer some interesting insights for theory development and empirical research in EEG, but does not claim that this is the only approach to EEG or that it should replace well-developed approaches in 'cultural turn' or political economic geographies. On the contrary, EEG based on GD is seen very much as complementary to those approaches that highlights particular aspects of regional economic change.

\section{The necessity and insufficiency of Generalized Darwinism}

Although Thorstein Veblen asked "Why is economics not an evolutionary science?" as early as 1898 , it was not until NELSON/WINTER's (1982) "An evolutionary theory of economic growth", that evolutionary principles started to find their way back into economics (for a good overview of the antecedents of evolutionary theorizing in economics see HodGSON 1993, 2001). However, while there are various journals dedicated to evolutionary economics (Journal of Evolutionary Economics; Industrial and Corporate Change), there is at the moment no single overarching theoretical framework, common methodology, empirical research programme or core concepts that ties the community together other than a rejection of the conceptual pillars of neoclassical economics, perfectly rational agents and equilib- 
rium (Nelson/Winter 1982). Stoelhorst $(2008,344)$ claims that there are a number of ontological commitments held among evolutionary economists including a focus on change, a need for causal explanation of change, and continuity, how things at time $t+1$ are derived from the state of things at time $t$. In addition, he identifies a commitment to a layered ontology in order to explain change at multiple, interrelated levels of analysis. The last point is important from an economic geographer's point of view, but it is less clear whether evolutionary economists recognize explicitly the need for a layered ontology.

Darwin's evolutionary theory attempts to explain how populations change over time, how everything can be traced back to common ancestors, and how the principles of variation, inheritance and selection produce adaptive fit. Darwin's most important contribution was his theory of natural selection based on population thinking that specifies a recursive causal logic based on the interplay of variation, inheritance and selection that can explain adaptive complexity without the need for a divine creator. "The algorithmic nature of Darwinism means that when there is selection pressure on a population of entities in combination with a mechanism to replenish the variation in this population and a mechanism to retain the variations that are selected, evolution will necessarily occur" (STOELHORST 2008, 347).

In order to get a better understanding of the power of Darwinism we need to discuss its logic in greater detail. The three principles of variation, inheritance and selection are necessary conditions for adaptive fit to occur. In order to obtain a functional explanation it is necessary to distinguish between replicator and interactor to complete a logical feedback loop between variety, retentive selection and differential reproduction. The principle of variation implies that if there is variation in a population of evolving entities, then there is a need to explain how such variation is created and replenished. The principle of selection implies that, in any given context, some entities have traits that allow them to live longer and to be more successful in producing copies of themselves than others resulting in differential survival, and this process requires explanation. The principle of inheritance refers to a broad class of mechanisms, including diffusion and other forms of replication, by which information concerning adaptations is passed on or copied through time (HODGSON/KNUDSEN 2010, 238 ff.).

According to Hodgson/KNUdSEN (2010), Darwinian principles apply to all complex population systems including biological and social systems. Complex population systems describe worlds where multiple, varied entities interact with their environment and each other. These entities face immediately (locally) scarce resources and struggle to survive through competition and cooperation. They adapt to their local environments and, if environments are stable enough to validate the utility of adaptations, they are replicated. The principles of variation, selection and inheritance can thus be generalized in the sense that all complex population systems are characterized by those common abstract features. It is a contention of a degree of ontological communality at a high level of abstraction $^{1}$ and not at the level of detail. Variation, replication and selection can be defined in general and abstract terms, but the particular mechanisms of variation, replication and selection will vary between different domains as the entities and processes involved vary and need to be complemented with auxiliary and particular explanations in the biological and social domains respectively. The concrete mechanisms of evolution in the social domain must be different from those in the biological domain, but that does not invalidate the ontological communality at a high level of abstraction. ${ }^{2}$ In the following the operation of the basic evolutionary principles variation, inheritance and selection are discussed in greater detail.

Variation provides the fuel for evolutionary change (Hodgson 2001; Metcalfe 1998; FosTER/MetCALFe 2001). Without variation in characteristics of selective significance evolution would grind to a halt and we would be stuck in equilibrium populated by representative (identical) entities that interact in a pre-determined and unchanging way. Change is then the result of shocks emanating from outside the system such as natural catastrophes, immigration of new species, wars or crop failure. In an evolutionary view variation is introduced through random mutation, technological change by purposive and forward-looking agents, recombination of existing characteristics, technologies, knowledge, habits or routines, import from other places, diffusion of existing characteristics, generative replication or successor selection. Once we accept the need for and understand 
the importance of variation for the evolutionary process, the exact mechanisms and causal drivers for the creation of variation need to be specified carefully in different domains. In particular the ability of humans to communicate through language and make decisions based on future expectations about the environment is important and one of the main drivers of change. Notice that intentional and forward looking agents are compatible with GD as long as the outcome of those actions cannot be predicted with certainty. While the principle of self-organization can explain the increase in variation, and how individual entities develop, it cannot explain why certain emergent properties, features or populations survive while others do not. Self-organization theorists such as KAUfMANN (1993) and DePEW/WEBER (1995) support this claim and argue that self-organization complements GD, but does not replace it. In order to understand why certain varieties survive, we need to introduce the principle of selection.

The second Darwinian mechanism is selection winnowing on existing variation. It is important to make clear at the outset that Darwinian selection does not entail "survival of the fittest", competition is not a defining characteristic of natural selection (LEWONTIN 1978) and selection does not lead to optimal or most efficient outcomes. Cooperation is at least as important as competition as behavioural economists and evolutionary theorists have demonstrated convincingly once we accept multilevel or group selection processes as essential part of evolution (SOBER/WILSON 1998; GINTIS et al. 2005; WILSON 2011; WILSON 2012). The probably most general definition of selection is offered by PRICE (1995): "Selection involves an anterior set of entities that is somehow being transformed into a posterior set, where all members of the posterior set are sufficiently similar to some members of the anterior set, and where the resulting frequencies of posterior entities are correlated positively and causally with their fitness in the environmental context. The transformation from the anterior to the posterior set is caused by the entities' interaction within a particular environment" (HODGSON/KNUDSEN 2010, 92). Price's definition offers a general description of the process and encompasses a lot of cases but does not explain why particular variants are selected rather than others. In order to get a better grasp of selection, it is useful to follow SOBER (1984) and distinguish between the selection of interactors or phenotypes (eg. firms) and the selection for replicators or genotypes (eg. firm routines). Selection refers to changes in the composition of a population and these changes are caused by a systematic relationship between fitness and survival.

Selection involves the selection of a subset of elements from an anterior set (eg. selection of a subset of firms after an industry shake out) where environmental interaction causes elimination to be differential (eg. selection eliminates the firms that made losses and as a result, their routines are removed from the population). If variation is not replenished, subset selection will eliminate entities until variation disappears. Whether or not firms survived or were eliminated because of decisions made by forward looking mangers or pure chance is inconsequential for the logic of the argument. (Subset) selection separates the generation of new variation from the process of selection but leaves unexplained the variation in the anterior set. In reality, there are multiple traits that are relevant for selection and that can be activated in response to changes in the environment. Changes in the environment results in selection for different traits and the ensuing replication process proceeds along a new path as a different subset survives. ${ }^{3}$ Environments do not have to be exogenous to the firm population but can be manipulated by powerful interest groups to stack the environmental constraints in their favour. Because of the ability to form expectations about the future, the feedback loop between variation and selection and thus the speed of evolution is much more rapid in sociocultural systems. ${ }^{4}$

Differential reproduction and survival can be independent of fitness, in which case it is called drift. Drift does occur, in particular in small populations and when confronted with flat fitness landscapes. In contrast to drift, selection requires differential survival rates to be related to some form of fitness. Fitness in social evolution can refer to a particular property of a replicator and the propensity of replicators with that property to produce copies and increase the frequency of similar replicators in the population through diffusion to other interactors (eg. knowledge transfer) or by making copies of the interactor (eg. spin-offs). An analysis of selection effects would require the identification of the causal effects of social replicators (eg. routines) on social interactors 
(eg. firms) which should be related to pressures of the particular environmental context in which the interactor operates. It is necessary to identify trait values and examine whether they covary with survival and/or replicative success. Survival rates or profit rates have been used as measures of fitness in industry evolution (KLEPPER 2001; BOSCHMA/WENTING 2007). Notice that selection appears to be an important force shaping the evolution of firm populations. The analysis of the evolution of US manufacturing industries revealed that about $10 \%$ of plants producing in year $t$ exit and about $10 \%$ of plants that did not exist in year $t$ enter in year $\mathrm{t}+1$ indicating that at any given time there are a large number of firm routines in operation that produce unviable firm characteristics and suggests that selection is indeed important for industry evolution. Those percentages increase rapidly if we look at five year or ten year periods (DUNNE et al. 1989; DAVIS at al. 1996; RigBy/EssletZBICHLER 2000). The high entry and exit rates are remarkable and illustrate that the variety-selection interaction operates at a rapid pace in a capitalist economy. Selection ensures continuity in populations (a requirement of Darwinian evolution) in two ways: either a particular subset of the original anterior set of entities survives (subset selection) or information about adaptive traits is passed on from the anterior set to the posterior set of entities (successor selection).

For selection to operate requires a certain level of stability in characteristics. While the environment acts on interactors and interactors adapt their behaviour triggered by environmental cues, the characteristics of the interactors are related to information stored in and passed on by replicators. A replicator is a structure hosted by the entity that is causally involved in the replication process. During its creation the copy must obtain the information that makes the copy similar to its source from the same source. Diffusion is a special case of replication that does not involve the copying of interactors but information transfer between existing interactors. This definition of replication is synonymous with inheritance. Theorists emphasizing the development side of the evolutionary process point out that the replicated information by itself is inadequate to provide a complete description of the emerging interactor. The replicator does not replicate by itself but includes building instructions for the development of interactors that are energized by par- ticular environmental stimuli. Those objections of development theorists can be accommodated through the introduction of the concept of generative replication. "Generative replicators are material structures that embody construction mechanisms (or programs) that can be energized by input signals that contain information about a particular environment. These mechanisms produce further instructions from a generative replicator to their related interactor that guide its development and so can lead to the evolution of structures that are potentially unbounded in complexity" (HoDGSON/ KNUDSEN 2010, 122).

The environment does not 'see' replicators and hence, replicating entities are not changed directly by the environment. Replicators do not become adapted instantaneously to those changes. As a result, information (adaptive experience) accumulated over generations and allowing for adaptation to different environments is preserved. Environments 'see' interactors. An interactor is an entity that interacts as cohesive whole directly with its environment and this interaction causes replication to be differential (HuLL 1988). For each interactor there is a set of corresponding replicators. It is implied that the replicators are relatively durable in comparison with their host interactor. For instance, habits and customs are passed on even if individuals hosting them die. To qualify HodGson/KNUDSEn (2010, 239 f.) propose that an interactor must satisfy a number of conditions. First, an interactor should be a relative cohesive entity with boundaries between itself and the surrounding environment. The internal relations among component parts are usually stronger than the external relations. Second, even if the environment shifts, the interactor has sustained integrity owning to the components of the interactor and the internal relations among them. Third, there is shared dependence of component replicators on the interactor. Fourth, every component replicator has to be within the boundary and part of the structure of the interactor. Fifth, there must be a set of properties of an interactor that, in interaction with the environment must be a major factor in determining the (possible different) posterior set of replicators of the anterior set of replicators. From an economic geographic point of view the question is whether territorial units can be interactors or whether location is only part of the environment acting on lower level interactors such as firms or individuals. Regions, 
Tab. 1: Interactors and component replicators at multiple levels

Social interactors

Individual

Organization (plant, firm, university, etc.)

Group (social class, gender, ethnic group, etc.) City

Region

State

Super-national unit
Component replicators

Gene, habit

Routine

Customs/culture; language systems

Customs/conventions, urban policy routines/institutions

Customs/conventions, regional policy routines/institutions

Customs, national policy routines/institutions, laws, scientific and technological system

Laws, scientific and technological system, routines and laws to manage inter-state system and engage as whole with other units

Source: own draft

states, labor market areas may act as coherent wholes that are maintained even if subcomponents such as workers, households, firms or organizations disappear, but whether they qualify as interactors will often depend on the specific empirical context.

If we accept the ontological communality of GD in the biological and social domains, how then can we apply it to understand evolution in the social domain? We need to understand how variation is produced, what constitute suitable social interactors and replicators and how interaction with the environment results in selection at multiple levels.

\section{Group selection and multi-level evolu- tionary processes in the social domain}

In order to understand a multi-level evolutionary process, social interactors and corresponding replicators need to be identified at each level. Examples of a hierarchy of social interactors and component replicators are provided in Tab. 1. For higher-level groups to qualify as social interactors, groups need to be integrated, cohesive and bounded entities whose component replicators (and the interaction among them) make them impervious in part to environmental change. The component replicators must be dependent on the survival of the interactor. This is relatively straight forward at the level of the individual or organizations as those entities may actually expire, but is trickier to conceptualize at the urban, regional or national scale. If interactions among component interactors are sufficiently strong so that their fate is tied up with the fate of the city, then cities may qualify as social interactors. Furthermore, component replicators must be within the boundary of the interactor and form part of its structure. And finally, the interaction of the group as an entity with its environment causes differential replication. Cities or regions with customs and institutions that bestow fitness advantages on groups or individual group members are more likely to grow than others. It is also clear that successful routines and institutions replicate through (imperfect) copying enabled by inter-urban communication between policy makers, the influence of global organizations or consultants informing urban policy makers (RoBINSON 2011). Fitness benefits emerge from membership in the group even if the behaviour generated is not necessarily optimal for the individual. Urbanization and localization economies could be conceptualized as fitness advantages that geographic context bestows on firms and individuals locating and interacting in particular places. For group selection to operate requires those advantages leading to differences between groups to be sufficiently strong to overcome selection forces on individuals or firms within a group and/or territory. This process can be captured through an expanded version of Price's equation that allows for the decomposition of group changes into group selection, individual selection and a transmission effect (changes within individuals or firms such as innovation; see PRICE 1970, 1995; FranK 1998; ANDERSEN 2004a, b).

While much of the work on group selection treats groups as an agglomeration of interact- 
ing individuals, there needs to be more consideration of its structural and binding features. According to HodgSON/KNUDSEN $(2010,163)$ "social structure refers to a set of significant social rules, social relations or social positions involving a multiplicity of individuals, with properties that are not properties of individuals taken alone". Groups, social as communities, firms, or other organizations are not reducible to individuals even though people learn as individuals and knowledge (in particular tacit knowledge) is stored as memory traces by each individual member. The reason is that those individual memory fragments "are not fully meaningful or effective except in the context provided by the fragments stored by other members" (WINTER 1982, 72). The enactment of tacit knowledge depends crucially on the existence of a structured context in which individuals interact with each other.

Group selection is critical to explain evolutionary transitions in biological and social evolution and required to explain an increase in adaptive complexity (SOBER/WILSON 1998; STOELHORST 2008). Work on cultural evolution ${ }^{5}$ suggests that cultural transmission effects can generate high degrees of conformism within groups and coupled with social sanctions and incentives can reduce free-riding. Cooperative individuals will experience a fitness advantage because of their use of socially transmitted skills and their conformity to socially sanctioned behaviour. Conformist and prestigebased transmission can generate positive feedback effects that result in clusters of behaviour that vary substantially between groups (RICHERSON/BOYD 2005; VAN DEN BERGH/GOWDY 2009). Accidental factors or small differences in the social environment can lead to path-dependent differences from group to group and especially from culture to culture. Of course, if the regulatory environment favours hedonistic behaviour, then the share of cooperative individuals in a group will decline. Context is critical here. While certain habits, customs or institutions may be beneficial in one environment they may cause destruction in another (MAYR 1963; WILSON 2011). Another important point to remember is that too much conformism can result in lock-in and mal-adaptation of the group and its members.

Based on the definition of an interactor, individuals, groups, organizations, or states would qualify as they interact as relatively bounded and cohesive wholes with their environment. Organizations are special types of institutions involving the criteria of establishing boundaries and distinguishing members from nonmembers, have decision making powers (i.e. they can make choices that are in part independent from other organizations), and have a chain of command to establish positions and relations between them as well as responsibilities and power associated with them. Social positions are irreducible to the individual occupying them at a particular time. Institutions are systems of rules that structure social interaction including norms of behaviour, social convention as well as legal and formal rules. Systems of language, money, law, traffic conventions, table manners and all organizations are institutions. More importantly in the context of this paper, institutions mediate social relations among groups and in particular places which in turn influence the efficiency of economic exchange. They influence the cost of finding resources, the probability of finding them and they regulate social access to them. Furthermore they affect transaction costs as systems of reward and punishment reduce the effectiveness of free riders and help build networks of trust (FAROLE et al. 2011). While the sustainability of social positions depends in part on habits of thought or individual behaviour, the organizational relation between individuals needs to be maintained and possibly replicated as well. Organizations are built on but are not reducible to individuals.

For groups to evolve requires that information about the group and its components is stored and replicated over time. We thus require component replicators that belong to social interactors. While genes are important to explain the evolution of instincts, they are not particularly helpful for explaining change at time scales relevant to human evolution. Given the lesser time scales, habits, routines and customs have sufficient stability to be considered as replicators. "Social replicators are mechanisms that help mold human capacities and that are transmitted, not genetically, but socially. [...] Habits are submerged repertoires of potential behaviour that can be triggered by an appropriate stimulus" (HodGSON/KNUdSEN 2010, 137). They are formed through the repetition of behaviour or thought, are influenced by prior activity and the basis of reflective and non-reflective behaviour. Habits replicate indirectly through behavioural expressions. They impel 
behaviour that is imitated by others and molded by incentives and constraints. Eventually, the copied behaviour becomes rooted in the habits of the follower. As habits often form in childhood through repetition of culturally specific behaviour, habits may develop differently or trigger different responses in different cultural contexts. Habits are stored in the nervous system, but their mechanism of replication differs from gene replication. Mechanisms of social conformity and prestige based behaviour are particularly important to weed out "errant" habits.

Moving from individuals to organizations, it is possible to think of routines as replicators of organizations. "A routine is a generative structure or capacity within an organization. Routines are organizational dispositions to energize conditional patterns of behaviour within organizations, involving sequential responses to cues that are partly dependent on social positions in the organization [...]. Routines depend on a structured group of habituated individuals, among whom many of these habits depend on procedural memory. The behavioural cues exhibited by some members of a structured assembly of habituated individuals trigger specific habits in other" (HoDGSON/KNUDSEN 2010, 140). These conditional, rule-like structures and algorithms are the key information mechanisms through which information is carried and processed. Rather than evaluating every possible outcome of an action, organizations follow rules-of-thumb that have proved useful adaptations in the wake of environmental change in the past. Routines are not behaviour, but mobilize behavioural responses if energized by environmental stimuli (eg. "if profits drop below a certain threshold, then invest in R \& D"). If the environmental stimulus disappears, the behaviour disappears, but not the underlying routine. Organizations can be characterized by emergent properties and capacities that are not possessed by individuals taken separately but that stem from the structured relations and causal interactions between the individuals involved. "The replication of routines includes the replication of organizational dispositions to activate cue-triggered patterns of behaviour within the organization as well as the replication of social positions that define roles associated with individual interactions and the performance of routines" (HODGSON/KNUDSEN 2010, 142). Replication can mean copying routines among plants of companies or the imita- tion of routines that work well elsewhere. The movement of workers between organizations or the hiring of consultants to transfer knowledge are mechanisms for routine replication. The acquisition of routines involves new conditional mechanisms that enable new responses to new types of information inputs rather than merely new information inputs to address existing challenges. Because routines need to be implemented in different organizational contexts and copying is imperfect, the number of potential responses to information input expands. Routine acquisition requires absorptive capacity and will induce copying errors and modification to fit with existing routines and cultures. If absorptive capacity is lacking or existing routines are too dissimilar to allow copying, the process may fail. Habits and routines are replicators at different levels of analysis, with habits attaching to individuals and routines to organizations.

While firms as organizational units are relatively straight forward to embed in an evolutionary economic framework, various organizations, subnational territorial entities, nation states and supra-national entities qualify as social interactors with corporeal and linguistic habits, social customs, writing systems, laws and scientific and technological knowledge forming potential component replicators. The fitness of groups may be interpreted as average fitness of group members or as the expected number of offspring of collectives which moves away from the individual based fitness concept. "Social evolution builds on sufficiently successful but imperfect survivals from the past. Any complex system is a linked structure of imperfect but rigid modular adaptations that were sufficiently successful in a given environment. Even if a modular component was highly efficient in the past it is unlikely to be as efficient in the changed circumstances. Yet, if imperfect component retains a functional role in the system, then it can be preserved through selection" (HodGSON/KNUDSEN 2010, 219-220). Because of the shorter time scales and more variable contexts, selection in social systems is less effective in producing adaptations (VAN PARIJS 1981). Because adaptation is never perfect and because the environment constantly changes, there is no gravitation to a social optimum or convergence to the highest possible level of productive efficiency. Furthermore, because what can be achieved in the future is constrained by adaptations to past environmen- 
tal conditions, path-dependence, frequency dependence and institutional complementarities result in increasing returns that impede instantaneous adjustment. And finally, while studying regional productivity or GDP/capital growth may be of interest, 'fitness' does not only refer to efficiency, but is determined through interaction with the environment, which is influenced by purposeful agents and hence, socially constructed. Indeed, if we accept the promise of a socially constructed selection environment, then analysis cannot be 'objective' or 'value-free' (BROWN 2012). We need to start with the social goal and then construct selection environments that increase the probability of obtaining the pre-specified goal.

While HodGson /KNUDSEN (2010) provide definitional clarity and formulate the basic principles of a particular brand of GD at an abstract level, they admit that the framework needs to demonstrate its utility by being able to guide, organize and stimulate research programs and develop middle range theories (MERTON 1968) that can be subjected to empirical scrutiny. Whether this is possible without relaxing some of the assumptions such as the replicator-interactor distinction still needs to be established (VROMEN 2007). For this paper, GD is used to help organize existing work labelled as EEG but also to identify some of the shortcomings of that work given the insights from GD.

\section{Generalized Darwinism and economic geography}

EEG needs to examine how the general processes of variety creation, retention and selection can be employed for a better understanding of the historically specific, inconstant, uneven and differentiated geography of capitalism. Although the evolutionary logic should unfold in any social system, the following discussion refers to evolution under capitalism. Capitalism is a mode of production where firms produce for sale on the market. Because prices are determined by the socially necessary cost of production plus supply and demand, firms with relatively inefficient routines are less likely to compete and eventually be driven from the market. Intra-capitalist competition is thus a necessary outcome of capitalism explaining the need for continual search for technologies that lower costs and/or fetch higher prices. Technological and organizational change, exploitation and spatial expansion are endogenous to capitalism resulting in a continual increase in technological and organizational varieties that provide the fuel for evolutionary change. Firms will also attempt to influence their institutional environment to stack selective pressures in their favour. The interaction of firms with their environment (markets and 'non-market' institutions) results in differential reproduction. If differential reproduction is causally related with the fitness of the firm it is called selection. Those firms that perform relatively better in specific environmental contexts are more likely to replicate their routines through spin-off and diffusion. Because firm behaviour rather than routines adapt quickly to changing environmental triggers, routines provide sufficient stability for selection to operate. The role of capitalism for the production, retention and selection of variety has been discussed in greater detail in RIGBY/EsSLETZBICHLER (1997) and ESSLETZBICHLER/RIGBY (2007, 2010) and does not need to be replicated here. Instead, using the insights of GD and group selection outlined above, it is necessary to think how the evolution of firms is embedded in a multi-level evolutionary process to gain a better understanding of the inconstant geography of capitalism. The section reviews existing work in EEG and explores how a stronger focus on GD could augment or complement existing work. In order to get a better understanding how geography may use and influence evolutionary theory it is useful to distinguish between evolution in regions and evolution of regions. ${ }^{6}$ Evolution in regions interprets regionspecific institutions as part of the regional selection environment, while the evolution of regions means that regional institutions are part of the structure that evolves.

Most of the existing work in EEG discusses the evolution of firms, technologies, products and industries in regions and region-specific assets, relations and institutions constitute part of the local selection environment that shape the evolution of the entities in the region. Regional success is then little more then the sum of the successes of the individual entities. The first question we need to answer is how variety is created in a region. The literature identifies several processes resulting in increased product, process and industrial variety such as chance (ARTHUR 1994; BOSCHMA/VAN DER KNAAP 1997; BOSCHMA/LAMBOY 1999; STORPER/WALKER 1989; WEBBER et al. 1992), import 
of new technologies, firms or industries (MARTIN 2010), diversity (ESSLETZBICHLER 2007), endogenous creation of novelty through technological change, recombinant innovation (FRENKEN et al. 2012), and imperfect replication through imitation. There is a substantial amount of literature on regional innovation systems that explains why certain regions and countries are more likely to produce innovations than others (BRAZYK et al. 1998, LUNDVALL 1988). More recent work in EEG has focused on the entry dynamics of firms. Entry rates depend on the number of incumbents in a region as source of spin-offs (ARTHUR 1994) as well as a signal to (re)locating firms (SUIRE/ VINCENTE 2009) explaining why regions with large numbers of successful firms tend to attract more entries (KLEPPER 2007; BOSCHMA/ WentING 2007). Furthermore, the increase in the number of products and technologies increases the probability to recombine them into new products or technologies resulting in rapidly expanding product and technology spaces (KAUFMANN 2010). While the windows of locational opportunity approach (BosCHMA/ VAN DER KNAAP 1997; BOSCHMA/LAMBOY 1999) as well as ARTHUR's (1994) model highlight the unpredictability of entrants in new industries, recent work on nursery cities found that entry in new industries increases in diversified cities while those in mature industries enter or relocate to specialized peripheries (Duranton/Puga 2001).

The second question that requires answering is how information stored in products, processes, and firm routines are replicated over time. This question is related to questions of path-dependence (ARThur 1994; Martin/Sunley 2006) and probably the most developed in EEG. Life cycle models based on spin-off dynamics (KLEPPER 2007; BosChMa/Wenting 2007) provide ample empirical evidence that information is (imperfectly) replicated through spin-offs from successful parent firms that tend to co-locate in the same region. Hence, the existence of successful firms results in higher rates of successful spin-offs which results in the clustering of an industry in the region. The idea of spinoff dynamics in existing industries has been complemented with ideas of industrial branching, related variety and recombinant innovation (NEFFKE et al, 2011; FRENKEN et al. 2007; FRENKEN et al. 2012). Here, new industries are more likely to emerge in regions where industries supplying related knowledge and skills necessary to develop a new technology are already successful (eg. coach building for car chassis design). Novelty in this model is thus produced incrementally and built on existing technologies which is very much in line with a Darwinian approach to evolution. Complementing this work are increasingly detailed studies examining the transfer of information and knowledge opening up the black box of 'knowledge spillovers' and investigating in detail the channels of information replication and diffusion including labor mobility (BosCHMA et al. 2009), input-output relations (FAN/ZHANG 2000) and patent citations (JAFFE et al. 1993; SONN/STORPER 2008). The analysis highlights the importance of geographical and cognitive distance impeding the flow of knowledge (JAFFE et al. 1993) and resulting in spatially localized search and adaptation processes. The work on 'related variety' engages with key economic geographic questions on the role of urbanization and localisation economies and proposes a more nuanced interpretation. Rather than copying identical or introduce very different forms of knowledge, the adaptation of related knowledge produces the greatest benefit for firms and industries (BoschMA et al. 2009, NEFFKE et al. 2011). For a detailed summary of this work see BosCHMA/FrENKEN (2011).

EEG based on GD could complement this research on the creation and replication of variety through an analysis of the impact of the regional selection environment on the pace and direction of regional economic change. The regional selection environment can consist of differences in relative factor prices (caused e.g. by differences in quantity and quality of the labor force, suppliers and customers, differences in regulatory frameworks) moving the creation and adoption of technologies in particular directions but also includes organizations such as labor unions, research universities, government, and the structure of the relations between those organizations. Assuming that individual behaviour is based on habits and firm and organizational behaviour is based on routines, then the selection for those habits and routines is related to their adaptation to the local environment. If interregional differences in selection environments exist (HALL/SOSKICE 2001; PECK/ THEODORE 2007), then different firms and organizations with different component replicators will be selected and only routines of selected organizations will replicate. Because organizations will also try to shape their environ- 
ment to favour their routines, the environment will co-evolve with individual entities and become adapted to the entities that replicated successfully (BOSCHMA/VAN DER KNAAP 1997; Boschma/Lamboy 1999; Schamp 2010). Localized search and adaptation processes coupled with a cumulative build-up of region specific infrastructure, supporting organizations and institutions will push regions along location specific pathways of technological and institutional change. The relative strength of developmental processes within entities versus selection effects need to be assessed empirically, but empirically observed differences in technologies even within relatively narrowly defined industries (ESSLETZBICHLER/RIGBY 2005; RigBY/EsSLETZBICHLER 2006) and high turnover among plant populations (RIGBY/ ESSLETZBICHLER 2000) suggest that selection may be a potent force to shape regional economic trajectories.

While regional institutions can shape regional development paths, they do not determine firm behaviour and performance (GERTLER 2010). Even within the same institutional environment, firm routines can vary widely (GUILIANI/ Bell 2005; Boschma/FrenKen 2011). However, the question here is not whether heterogeneity disappears, but whether the population of routines and associated behaviours as well as industry compositions change over time as a result of institutional influences and how the institutional environment is shaped by the interests of existing actors. Recent work on the causes of regional growth differences attributes them to differences in regional institutional environments such as community and society (FAROLE et al. 2011).

Because entities and environments co-evolve we can expect resources being directed towards improving the efficiency of firms and organizations within regionally dominant industries at the expense of activities that would stimulate the creation of new products and industries. Examples would be policy decisions in favour of the financial sector at the expense of manufacturing in places like London or New York. Even if individual firms and subordinate sectors would thrive outside the region, the allocation of in-regional resources away from them or their supporting (supplier and customer) networks and infrastructure at the expense of the dominant industry could result in exit. The advantages are aggregate efficiency gains through spillovers between related industries and localization economies. The disadvantage is that strong technological and industrial specialization coupled with strong ties among regional agents and dominance of regional institutions can result in regional lock-in (HASSINK/SHIN 2005). GRABHER's (1993) study of the German Ruhr area demonstrates how the focus on coal, iron and steel coupled with strong ties among major firms, suppliers, customers and politicians resulted in functional, cognitive and political lock-in that impeded the creation of technological and industrial variety. Lock-in was only recognized as problem by regional actors when output and employment declined irreversibly. It was only at the point of crisis that coordinated action was taken to change the institutional environment to re-allocate resources and refocus economic activity on alternative technologies, sectors, skill sets and networks. It is in those cases of negative lock-in that the region as relatively cohesive unit characterized by institutions, sectoral composition, technologies, skill-sets, infrastructure comes into focus. GRABHER's (1993) example demonstrates that the neglect of extraregional economic and technological developments results in strong adaptation of regional actors to region-specific environments that reduces adaptability to future economic change occurring outside the region and imposed by the logic of capitalist accumulation (RAMMEL/VAN DEN BERGH 2003).

It would be difficult to understand the decline of the Ruhr area by simply looking at the evolution of its firms without taking into account changes occurring elsewhere. On the one hand, strong local social ties, stronger intra- than extra-regional relations among component interactors and the local institutional environment producing region-specific replication and selection criteria insulated firms from global selection pressures. Software and other supplier firms in the Ruhr area failed to diversify and explore markets beyond the locally dominant coal, iron and steel cluster because it was efficient for them not to do so. There was no need to divert resources to energize routines responsible for search activities, marketing or acquiring personal with different skill sets because routines managing the business-as-usual process returned sufficient profits for them to survive. Some of the search routines sustained by particular departments within firms may even have been eliminated resulting in limited ca- 
pacity for product and technology search outside the region. The same software firm somewhere else might have been driven out of business much earlier if it failed to adapt to changing economic conditions. In the case of the Ruhr area, the regional institutions did not adapt to global economic change, such that firms, in turn, became unable to recognize the need to change their routines.

SAXENIAN's (1994) comparison between Silicon Valley and Route 128 offers another illustrative example how individual habits, local firm routines and the regional configuration of social networks coupled with regional culture enables or frustrates rapid adaptation to constantly changing economic conditions triggered by rapid technological change. Firms required routines that mobilized organizational capacities to cope with technological and market uncertainties related to fast technological change. The fact that firms moved research operations and workers migrated from East to West coast suggests that firm routines were neither rapidly changeable in situ nor were they simply copied in another place. Instead spatial relocation was a strategy to access novel routines and tap into new institutional environments. Workers unable to apply their skills in one local context were able to mobilize the same set of skills in another institutional and social context. In this case, place as particular ensemble of social relations and institutions contributes to an understanding of the success and failure of individual entities and illustrates that spatial isolation can play an important role for stimulating or stifling the creation of variety. The example does not suggest that we should return uncritically to the environmental determinism and spatial fetishism of the 1950s, but highlights the need to move away from a narrow focus on the evolution of individual entities in EEG. In the case of the emergence of transistor and semiconductor based computer technology in the US, the competitive performance of individual entities could only be unleashed in particular spatially localized socioinstitutional contexts. Why those conditions existed in one place but not others has a lot to do with path-dependent technological and organizational change at the firm scale as well institutional sclerosis at the regional scale and with a number of historical accidents unpredictable before history ran its course. In this sense, national and global markets not only evaluate individual entities in places but also the socio-institutional contexts of places themselves.

BERMAN/BuI's (2001) analysis of the effect of lower emission targets for Californian oil refineries on firm emissions and productivity is another example of the role of institutions on the evolution of firm populations and differential survival of their routines. Because lower emission targets in California forced firms to introduce newer, cleaner technologies (that happened to be more productive than existing technologies) earlier than their Texan competitors, they outperformed them in terms of lower environmental emissions and, as unintended by-product of the regulation, higher productivity. Differences in the regional institutional environment (in this case environmental regulation) resulted in increased fitness of plants in the region that cannot be explained exclusively by endogenous transformation, industrial branching or simple routine replication. SPICER et al. (2000) demonstrated how major ruptures (in his case the collapse of communist regimes) can transform the selection environment of firms resulting in the elimination of firms and their routines previously sheltered from international competition. In a different analysis, MuRmann (2003) attributes the success of German synthetic dye industries to key institutional innovations (such as patent law and university-industry collaborations) rather than efficiency advantages of individual firms. The work by 'cultural turn' geographers (MCDoweLL 1997; THRIFT 2000) offer ample evidence on the role of local and corporate culture exerting influence on firm decisions using detailed case study approaches. Even if there are cases where institutions play a subordinate role to the endogenous creation of variety in firms for explaining the pace and direction of regional change they are essential for completing the explanatory loop of regional change in EEG (ESSLETZBICHLER 2009; MCKINNON et al. 2009). Rather than separating institutional economic geography from EEG and examine the co-evolution of firms, technologies and institutions at the intersection of the two approaches as Boschma/Frenken (2006, 2009, 2011) suggest, an EEG based on GD states that the coevolution of economic entities and institutions at multiple spatial scales should be at the center of a geographical evolutionary theory.

The work on group selection indicates that groups are subject to selection and that the evo- 
lution of socially intelligent beings cannot be explained satisfactorily without group selection (SOBER/WILSON 1998; WILSON 2011; WILSON 2012). A number of studies has shown that the fragmentation of national or regional societies into competing groups (eg. ethnic or language differences) claiming shares of regional resources (including public sector contributions) results in inefficient investment patterns (EASTERly/DeVine 1997; Alesina et al. 1999) which in turn, affect the aggregate growth path of a region or country. Recent theoretical developments in evolutionary theory around notions of group selection offer an interesting angle for the analysis of group formation and behaviour and their ability to exert power over others (SAFARZYNSKA/VAN DEN BERGH 2010). Although still in its early stage and primarily concerned with the emergence and survival of altruistic behaviour, this work recognizes the importance of power relations, social positions and systems of reward and punishment and offers explanations that are consistent with evolutionary theory. Models of group selection could be employed to generalize insights from case studies in order to identify common causal processes to explain how stratification of regional societies into groups with differential access to resources influence regional economic change. GD could thus offer formal models that may be of interest to economic theorists trying to understand regional differences in growth trajectories. The other insight from group selection and GD is an understanding of evolution as unfolding at multiple, related levels. In order to understand why regions such as the Ruhr area saw their economic trajectories reversed, highlights the need to embed the evolution of individual entities and institutions in a broader, hierarchical evolutionary process, and this means we need to address not only the evolution of entities in regions but also the evolution of regions.

The relevance of different scales will vary with empirical context but the stylized hierarchy of spatially nested entities depicted in Tab.1 helps to develop the theoretical arguments for a multi-level EEG. Evolution is not reducible to evolution at the level of the individual or firm. A multi-level conceptualization of evolution avoids methodological reductionism implied by MACKINNON et al. (2009). Individuals, groups, firms, regions, states, supra-national entities are internally heterogeneous and carriers of information irreducible to information at lower levels (habits, routines, customs, social norms, law), and while relatively stable in the short-run, are the outcome of long-term economic and political struggles among individuals and between groups. A number of key issues are brought into focus. What are the social interactors and replicators at different scales? How does the regional selection environment influence evolution at lower and higher scales of analysis? How does the dominant business culture become 'hardwired' in the habits and routines of individuals and organizations and how does it spread between regions? What maintains those routines even if the success of those routines for improving the relative economic positions of firms becomes questionable? What does 'regional' success or failure mean in an evolutionary context?

The algorithmic logic of Darwinism as variety generation, replication/retention of information and selection can be extended to evolution at higher spatial scales including countries or supra-national entities such as the EU. Countries, like regions compete for investment, skilled workers and firm start-ups and can be considered as relatively cohesive entities characterized by common institutional features that influence component regions, social groups, firms and individuals and their respective institutions, social norms, routines and habits. Rather than trying to find a comprehensive list of interactors and replicators, it is important to identify those that are of selective significance for the empirical question posed. Even if different kinds of institutions may exert causal power at different levels and in different contexts, the need to identify interactors and replicators in evolutionary analysis can guide comparative research that would allow a more systematic analysis of the relationship between individual habit formation, firm routines and institutions at various spatial scales. FAROLE et al. (2011) identify community and society and their relationship to long-term regional growth as possible starting points for a systematic analysis in economic geography and specifically highlight the need to study the links of institutions evolving at different spatial scales as well as their influence on firms and individuals.

Although we may consider regions as social interactors, does that really mean that regions rather than their constituent parts such as firms or workers compete with each other for scarce 
resources, jobs and market shares? Although regions do not compete in the same way as firms do (KRUGMAN 1995), the rolling out of the neoliberal state (PECK/TICKELL 2002) meant that the discourse around regional competitiveness as regional development strategy has become dominant (BRISTOW 2005; HARVEY 1989). This discourse is based on changes in the material world where inter-regional competition for skilled labor, investment and new firms has intensified as transfer payments between regions have been drying up. Those changes are theorized in the literature on geographic scale commenting on the changing role of the state vis-àvis regions and supra-regional entities (eg. BRENNER 2004). What is less clear from this literature is how institutional changes at the global scale re-structured the selection environment in which states, regions and firms operate and how this restructuring impacted on the economic performance of places and firms given pre-existing regional institutional environments. Explaining neoliberalism as new key ideological construct to govern economies also requires changes in individual habits that have not been explained in this literature but that points to the need of studying interactions between entities and their environment at multiple levels of analysis. An evolutionary approach could provide an overarching theoretical framework that encompasses and complements political economic and cultural approaches in economic geography as it encourages the analysis of change at and interaction between multiple scales from the individual to the global. While GD can provide an overarching ontology and general models of group selection to organize work in political economy and cultural turn approaches in economic geography, it cannot provide the detailed causal processes that explain those changes. They need to come from social theory, economics, psychology and geography.

\section{Conclusion}

Evolutionary economic theorists are united in their emphasis on change, the need for causal explanation of change, and continuity, how things at time $t+1$ are derived from their state at time $t$. In addition, evolutionary theorists believe in a layered ontology to explain change at multiple, interrelated levels of analysis and discard methodological reductionism: There are no foundational entities and explanations at one level cannot be reduced to explanations at a lower or higher level. Evolutionary theorists also believe in non-teleological thinking. The future is unpredictable and does not gravitate towards a pre-determined end. Many geographers are likely to agree with those principles, while many economists are not. GD is a particular theory of evolution that postulates that change in complex population systems is the result of processes generating, replicating and trimming variety. While the ontological foundations of GD are relatively well developed, theory development and empirical analysis informed by GD lacks behind. This paper does not remedy this shortcoming but suggests GD as overarching framework to organize existing work in EEG, identify strengths and shortcomings of EEG when interpreted through the lens of GD and emphasizes the need to embed institutions in EEG to close the explanatory feedback loop between variety, retention and selection. It also points to the possibility to expand EEG to an analysis of the evolution of regions rather than focusing exclusively on evolution of lower level entities in regions.

What then does a closer link to GD offer EEG in particular and economic geography in general? While complexity science, the principles of emergence and path-dependence are all important conceptual frameworks for understanding the evolution of regions, those frameworks can be regarded as components rather than alternative theoretical frameworks to GD. However, because GD is situated at a high level of abstraction it is insufficient to explain the detailed causal mechanisms of change in the social domain. The causal mechanisms that create, replicate and trim variation need to be developed for the social sciences and cannot be imported from biology. Given current research in EEG, a stronger link to GD would push evolutionary economic geographers to complement their work on the creation and retention of variety in the region with an analysis of the role of regional institutions impacting on the evolution of entities in the region and the replication and selection of those institutions. Rather than leaving the analysis of institutions to 'institutional geography' they need to be at the center of EEG.

GD proposes evolution to proceed at various levels, where evolution at one level is linked but does not determine evolution at other levels. In this sense it can provide a link between 
different sub-disciplines in economic geography that focus on different levels of analysis (individual, firm, industry, region, class, gender, ethnicity, networks). GD provides a conceptual link between analyses at the micro to the macro linking the evolution of habits to the evolution of routines, social norms, culture and institutions. While it will be impossible to study change at each level in a single research project, it may result in exciting collaborate research bridging different theoretical schools and systematically building up empirical research to get a detailed understanding of the inconstant geography of capitalism.

Related to this, GD could provide models of group selection to generalize findings from the large number of existing case studies providing a stronger feedback between theory development and empirical research. Those models could also be used as focusing device for setting up comparative case studies that allow a systematic comparison of regional institutional differences and their impact on regional growth, decline or other processes of interest. While anecdotal evidence is important, generalization can help establishing the common factors and processes linked to desirable or undesirable outcomes.

And finally, evolutionary theory has an important political dimension. Evolutionary theory requires a stronger emphasis on normative issues and explicit discussion of social values. Because evolution does not optimize, we cannot consider markets as optimizing institutions. Markets like many other institutions are part of a selection environment that is, in part, socially constructed by intentional agents and that shapes the evolution of lower level entities. While capitalist markets exert a particular logic on firms that require them to take decisions to make a profit, there is no a priori reason to suggest that this historically specific selection environment is optimizing or cannot be changed to obtain alternative goals. In this sense, evolutionary theory can evolve into a scientifically and socially progressive research programme.

\section{Acknowledgement}

I would like to thank two anonymous referees and Eike Schamp for their excellent comments on an earlier draft of the paper.

\section{Notes}

1 Levels of abstraction are levels within theories, while ontological levels refer to levels in different structures of reality.

2 Notice that ontological communality does not mean that social phenomena are reducible to biological or physical explanations, but only that the interaction of variation, inheritance and selection operates in all complex population systems to which social systems belong.

3 For instance, the key traits of innovating firms operating at a fast changing knowledge frontier may be a creative and well trained workforce to rapidly absorb and build on changes in knowledge, while the key traits for large firms applying and translating new knowledge into commercial products may be hierarchical structures and a workforce that follows strictly existing routines. The identification of relevant interactors, replicators and traits depends on the empirical context.

4 Richerson/Boyd (2005, 187) argue that culture evolved as adaptation to cope with rapidly changing physical environments in the Pleistocene. Imitation of successful individuals and conformism (imitation of what others are doing) have, according to their view, been selected for because it increases adaptability to different environments. In that sense, "culture is built for speed, not comfort".

5 "Culture is information capable of affecting individuals' behaviour that they acquire from other members of their species through teaching, imitation, and other forms of social transmission" (RICHERSON/BOYD 2005, 5).

6 Although the region is not an internally homogeneous system that could be neatly characterized by representative agents, organizations or institutions, regions can often be considered as "cohesive entities that have some capacity for retaining and replicating solutions to problems" (HodGSON 2009, 170). It is useful to start with a relatively simple notion of the region as a space containing elements (individuals, firms, workers, households, organizations, built environment), relations (social networks, traded and untraded interdependencies between firms and organizations) and comprising region-specific institutional environments (regional technology and science policies, laws, markets, culture, ideology, customs) where location in the region influences the evolution of those elements and relations in a similar manner.

\section{References}

Alesina, A./ Baqir, R./Easterly, W. (1999): Public goods and ethnic divisions. In: Quarterly Journal of Economics, 114, 1243-1284.

Andersen, E. (2004a): Population thinking, Price's equation and the analysis of economic evolution. (Paper submitted to Evolutionary and Institutional Economics Review).

Andersen, E. (2004b): From Schumpeter's failed econometrics to modern evometric analysis. Creative 
destruction as a tale of two effects. Milan. (Paper presented at the Conference of the International Schumpeter Society, Milan, 9-12 June).

ARTHUR, B. (1994): Increasing returns and path dependence in the economy. Ann Arbor.

BERMAN, E./ BUI, L.(2001): Environmental regulation and productivity: Evidence from oil refineries In: Review of Economics and Statistics, 83, 498-510.

Boschma, R./ ERIKSSON, R./LindGREN, U. (2009): How does labour mobility affect the performance of plants? The importance of relatedness and geographical proximity. In: Journal of Economic Geography, (9)2,169190.

Boschma, R./ FrenKen, K. (2006): Why is evolutionary economic geography not an evolutionary science? In: Journal of Economic Geography, 6, 273-302.

Boschma, R./ Frenken, K.(2009): Some notes on institutions in evolutionary economic geography. In: Economic Geography, 85, 151-158.

Boschma, R./ Frenken, K. (2011): The emerging empirics of evolutionary economic geography. In: Journal of Economic Geography, 11, 295-308.

Boschma, R./ LAmbooy, J. (1999): Evolutionary economics and economic geography. In: Journal of Evolutionary Economics, (9)4, 411-429.

Boschma, R./ Martin, R. (eds) (2010): Handbook of evolutionary economic geography. Cheltenham.

Boschma, R./ VAN DER KNAAP, G.A. (1997): New technology and windows of locational opportunity: Indeterminacy, creativity and chance. In: Reijnders, J. (Ed.): Economics and evolution. Cheltenham/Lyme, 171-202.

Boschma, R./ Wenting, R (2007): The spatial evolution of the British automobile industry. Does location matter? In: Industrial and Corporate Change, 16, 213-238.

BraczyK, H.-J./ CoOKe, P./Heidenreich, M. (1998): Regional innovation systems. London.

BRENNER, N. (2004): New state spaces. Oxford.

BRISTOw, G. (2005): Everyone's a 'winner': problematising the discourse of regional competitiveness. In: Journal of Economic Geography, (5)3, 285-304.

Brown, C. (2012): Transmutability, generalized Darwinism and the limits to conceptual integration. In: Cambridge Journal of Economics. Advance Access, doi:10.1093/cje/bes016.

Davis, S.J./ Haltiwanger, J. /Schuh, S. (1996): Job creation and destruction. Cambridge MA.

DenNeTt, D. (1995): Darwin's dangerous ideas. Evolution and the meanings of life. London.

DePew, D.J./ WeBer, B.H. (1995): Darwinism evolving. Systems dynamics and the genealogy of natural selection. Cambridge MA.

Dunne, T./ Roberts, M./SAmuelson, L. (1989) : The growth and failure of U.S. manufacturing plants. In: Quarterly Journal of Economics, 104, 671-698.

Duranton, G./ PugA, D. (2001): Nursery cities: urban diversity, process innovation, and the life cycle of products. In: American Economic Review, 91, 1454-1477.
Economic Geography (2009): Debate on evolutionary economic geography. In: Economic Geography, 85, 119-182.

Easterly, W. /Levine, R. (1997): Africa's growth tragedy: Politics and ethnic divisions. In: Quarterly Journal of Economics, 112, 1203-1250.

EssletzBiChleR, J. (2007): Diversity, stability and regional growth in the United States, 1975-2002. In: Frenken, K. (Ed.): Applied evolutionary economics and economic geography. Cheltenham, 203-229.

EsSLETZBICHLER, J. (2009): Evolutionary economic geography. Institutions, and political economy. In: Economic Geography, 85, 159-166.

ESSLETZBICHLER, J. (2012): Evolutionary economic geographies. In: Barnes, T./ Peck, J./ Sheppard E. (Eds.): The Wiley-Blackwell companion to economic geography. Blackwell, 183-198.

EssletzBichler, J./ Rigby, D. L. (2005): Competition, variety and the geography of technology evolution. In: Tijdschrift voor Economische en Sociale Geografie, 95, 48-62.

EssletzBichler, J./ RigBy, D.L. (2007): Exploring evolutionary economic geographies. In: Journal of Economic Geography, 7, 549-571.

Essletzbichler, J./Rigby, D.L. (2010): Generalized Darwinism and evolutionary economic geography. In: Boschma, R./ Martin, R. (Eds.): Handbook of evolutionary economic geography. Cheltenham, 43-61.

FAN, J.P.H./ LANG, L.H.P. (2000): The measurement of relatedness. An application of corporate diversification. In: The Journal of Business, 73, 629-660.

Farole, T./ Rodriguez-Pose, A./ Storper, M. (2011): Human geography and the institutions of economic growth. In: Progress in Human Geography, 35, 58-80.

Foster, J. / Metcalfe, S. (eds) (2001): Frontiers of evolutionary economics. Cheltenham/Northampton, MA.

FrANK, S.A. (1998): Foundations of social evolution. Princeton NJ.

Frenken, K. (Ed.)(2007): Applied evolutionary economics and economic geography. Cheltenham.

Frenken, K./ VAn OORT, F./ VerburG, T. (2007): Related variety, unrelated variety and regional economic growth. In: Regional Studies, 41, 685-697.

FrenKen, K./ IZQUIERDO, L.R./ ZEPPINI, P. (2012): Recombinant innovation and endogenous technological transitions. Eindhoven. (Working Paper 12.01. Eindhoven Center for Innovation Studies, Eindhoven University of Technology, The Netherlands).

GERTLER, M. (2010): Rules of the game. The place of institutions in regional economic change. In: Regional Studies, 44, 1-15.

Gintis, H./ Bowles, S./ Boyd, R./ Fehr, E. (Eds.) (2005): Moral sentiments and material interests. The foundation of cooperation in economic life. Cambridge, MA.

GrabHER, G. (1993): The weakness of strong ties. The lock-in of regional development in the Ruhr area. In: 
Grabher, G. (Ed.): The embedded firm. London, 255277.

Guiliani, E./ Bell, M. (2005): The micro-determinants of meso-level learning and innovation. Evidence from the Chilean wine cluster. In: Research Policy, 34, 4768.

Hall, P./Soskice, D. (Eds.) (2001): Varieties of capitalism. The institutional foundations of comparative advantage. Oxford.

HARVEY, D. (1989): The condition of postmodernity. Oxford.

Hassink, R./ Shin, D.H. (2005): Guest editorial: The restructuring of old industrial areas in Europe and Asia. In: Environment and Planning A, 37, 635-356.

Hodgson, G. (1993): Economics and evolution. Bringing life back into economics. Oxford.

Hodgson, G. (2001): How economics forgot history. The problem of historical specificity in social science. London, New York.

Hodgson, G. (2009): Agency, Institutions, and Darwinism in volutionary economic geography. In: Economic Geography, 85, 167-174.

Hodgson, G./ Knudsen, T. (2010): Darwin's conjecture. Chicago.

Hull, D. (1988): Science as a process. An evolutionary account of the social and conceptual development of science. Chicago.

Jaffe, A.B./ Trajtenberg, M./ Henderson, R. (1993): Geographic localization of knowledge spillovers as evidenced by patent citations. In: Quarterly Journal of Economics, 108, 577-598.

Journal of Economic Geography (2007): Special Issue: Evolutionary economic geography. In: Journal of Economic Geography, 7, 537-672.

Kauffman, S. (1993): The origins of order. Self-organization and selection in evolution. New York.

Kauffman, S. (2010): Reinventing the sacred. New York.

KLEPPER, S. (2001): The capabilities of new firms and the evolution of the U.S. automobile industry. In: Industrial and Corporate Change, 11, 645-666.

KLEPPER, S. (2007): Disagreements, spinoffs, and the evolution of Detroit as the capital of the U.S. automobile industry. In: Management Science, 53, 616-631.

Krugman, P.R. (1996): Making sense of the competitiveness debate. In: Oxford Review of Economic Policy, (12)3, 17-25.

LEWONTIN, R. (1978): Adaptation. In: Scientific American, 239, 212-230.

LUNDVALL, B.A. (1988): Innovation as an interactive process. From user-producer interaction to the national System of innovation. In: Dosi, G./ Freeman, C./ Nelson, R./ Silberberg, G./ Soete, L. (Eds.): Technical change and economic theory. London/New York, 349369.

MacKinnon, D./ Cumbers, A./ Pike, A./ Birch, K./ MCMAster, R. (2009): Evolution in economic geography: institutions, political economy and adaptation. In: Economic Geography, 85, 129-150.
MARTIN, R. (2010): Rethinking regional path-dependence: Beyond lock-in to evolution. In: Economic Geography, 86, 1-27.

Martin, R./ Sunley, P. (2006): Path dependence and regional economic evolution. In: Journal of Economic Geography, 6, 395-437.

Martin, R./ Sunley, P. (2007): Complexity thinking and evolutionary economic geography. In: Journal of Economic Geography, 7, 573-601.

Martin, R./ SunLEY, P. (2011): Forms of emergence and the evolution of economic landscapes. Utrecht. (Papers of Evolutionary Economic Geography 1116).

MAYr, E. (1963): Animal species and evolution. Cambridge MA

McDowell, L. (1997): Capital culture. Gender at work in the city. Oxford.

Merton, R. (1968): Social theory and social structure. New York.

Metcalfe, S. (1998): Evolutionary economics and creative destruction. London/New York.

Murmann, J. P. (2003): Knowledge and competitive advantage. The co-evolution of firms, technology and national institutions. Cambridge.

NefFKe, F./ Henning, M./ Boschma, R. (2011): How do regions diversify over time? In: Economic Geography, 87, 237-265.

NELSON, R., WinTER, S. (1982): An evolutionary theory of economic growth. Cambridge, MA.

Peck, J./ Theodore, N. (2007): Variegated capitalism. In: Progress in Human Geography, 31, 731-772.

PeCK, J. A./ TiCKell, A. (2002): Neoliberalizing Space. In: Antipode, 34, 380-404

Plummer, P./ ShePpard. E. (2006): Geography matters. Agency, structures and dynamics at the intersection of economics and geography. In: Journal of Economic Geography, 6, 619-638.

PrICE, G.R. (1970): Selection and covariance. In: Nature, 227, 520-521.

PRICE, G.R. (1995): The nature of selection. In: Journal of Theoretical Biology, 175, 389-396.

RAMmel, C./ VAN DEN Bergh, J.C.J.M. (2003): Evolutionary policies for sustainable development. Adaptive flexibility and risk minimizing. In: Ecological Economics, 47, 121-133

Richersen, P.J./ Boyd, R. (2005): Not by genes alone. How culture transformed human evolution. Chicago/London.

Rigby, D./ Essletzbichler, J. (1997): Evolution, process variety, and regional trajectories of technological change in U.S. manufacturing. In: Economic Geography, 73, 269-284.

RigBy, D.L./ J. EssletZBichler (2000): Impacts of industry mix, technological change, selection and plant entry/exit on regional productivity growth. In: Regional Studies, 33, 333-342.

RigBy, D.L/ EssletzBichler, J. (2006): Technological variety, technological change and a geography of production techniques. In: Journal of Economic Geography, 6, 45-70. 
RoBInson, J. (2011): The spaces of circulating knowledge. City strategies and global urban governmentality. In: McCann, E./ Ward, K. (Eds.): Mobile urbanism. Minnesota.

SAFARZynska, K./ VAN den Bergh, J.C.J.M. (2010): Evolving power and environmental policy: Explaining institutional change with group selection. In: Ecological Economics, (69)4, 743-752.

SAXENIAN, A. (1994): Regional advantage. Harvard MA.

Schamp, E. (2010): On the notion of co-evolution in economic geography. In: Boschma, R./ Martin R. (Eds.): Handbook on evolutionary economic geography. Cheltenham, 432-449.

Schubert, C. (2012): "Generalized Darwinism" and the quest for an evolutionary theory of policy making. Jena. (Papers on Economics and Evolution 0910, Max Planck Institute).

Sober, E. (1984): The nature of selection. Evolutionary theory in philosophical focus. Cambridge MA.

SoBER, E./ WiLson, D.S. (1998): Unto others. The evolution and psychology of unselfish behavior. Cambridge MA.

SONN, J.W./ StORPER, M. (2008): The increasing importance of geographical proximity in knowledge production. An analysis of US patent citations, 1975-1997. In: Environment and Planning A, 40, 1020-1038.

Spicer, A./ McDermott, G./ Kogut, B. (2000): Entrepreneurship and privatization in Central Europe. The tenuous balance between creation and destruction. In: Academy of Management Review, 25, 630-649.

Stoelhorst, J.W. (2008): The explanatory logic and ontological commitments of Generalized Darwinism. In: Journal of Economic Methodology, 15, 343-363.

STORPER, M./ WALKER, R. (1989): The capitalist imperative. New York.

Suire, R./ Vicente, J. (2009): Why do some places succeed when others decline? A social interaction model of cluster viability. In: Journal of Economic Geography, 9, 381-404.

Thrift, N. (2000): Pandora's Box? Cultural geographies of economies. In: Clark, G.L./ Feldman, M.P./ Gertler, M.S. (Eds.): The Oxford handbook of economic geography. Oxford, 689-704.

VAN DEN BERGH, J.C.J.M./ GowDy, J. (2009): A group selection perspective on economic behavior, institutions and organizations. In: Journal of Economic Behavior and Organization, 72, 1-20.

VAN PARIJS, P. (1981): Evolutionary explanations in the social sciences. An emerging paradigm. London.

VEBLEN, T. (1898): Why is economics not an evolutionary science? In: Quarterly Journal of Economics, 12, 373-397.

VRBA, E. S./ Gould, S.J. (1986): The hierarchical expansion of sorting and selection. Sorting and selection cannot be equated. In: Paleobiology, 10, 217-228.

VRomen, J. (2004): Conjectural revisionary economic ontology. Outline of an ambitious research agenda for evolutionary economics. In: Journal of Economic Methodology, 11, 213-247.

VRomen, J. (2007): Generalized Darwinism in evolutionary economics. The devil is in the details. Jena. 7(Papers on Economics and Evolution 0711, Max Planck Institute).

Webber, M./Sheppard, E./Rigby, D. (1992): Forms of technical change. In: Environment and Planning A, 24, 1679-1709.

WILsON, D. S. (2011): The neighborhood project. Using evolution to improve my city, one block at a time. New York.

WiLson, E.O. (2012): The social conquest of earth. London.

WINTER, S. (1982): An essay on the theory of production. In: Hymans, S.H. (Ed.): Economics and the world around it. Ann Arbor, 55-91 